\title{
KONTAMINASI ESCHERICHIA COLI PADA MAKANAN JAJANAN DI KANTIN SEKOLAH DASAR NEGERI WILAYAH DENPASAR SELATAN
}

\author{
Dewi Nuryani ${ }^{1 *}$, Nyoman Adi Putra ${ }^{2)}$, Ida Bagus Sudana ${ }^{3)}$ \\ 1) Dinas Kelautan dan Perikanan Provinsi Bali \\ ${ }^{2)}$ Fakultas Kedokteran Universitas Udayana, Denpasar \\ 3) Program Studi Magister Ilmu Lingkungan Pascasarjana Universitas Udayana, Denpasar \\ *)Email : dewi.nuryani@ymail.com
}

\begin{abstract}
Snacks at the Public Elementary School Canteen has a huge potential in the nutrition of schoolchildren, as it also has a level of vulnerability that can cause diarrhea if not to be improved maximally .The purpose of this study was to determine the factors associated with the incidence of E. coli contamination in snacks in the canteen of the Public Elementary School at area of South Denpasar District. The research was conducted with cross-sectional design on 31 canteen of Public Elementary Schools in at area of South Denpasar District in January to March 2015. The statistical test used was chi-square method. Positive E. coli contamination in food snacks of the Publick Elementary School Canteen at area of South Denpasar District were occur in amount of $71 \%$ and $29 \%$ negative. The factors related to the E. coli contamination in the snacks were foodstuffs $(p=0.037)$, storage of foodstuffs $(p=0.041)$, food- processing $(p=0.037)$, sanitary facilities ( $p=0.015)$ and power handlers $(p=0.037)$. The most dominant factors related to E. coli contamination in snacks of the canteens of Public Elementary School at area of South Denpasar District is sanitation facilities especially the water which have been used in process of the food-snack preparation .Suggested to all state elementary school cafeteria Region South Denpasar to improve environmental sanitation and water sources are more hygienic .
\end{abstract}

Keywords: E.coli contamination ; snack; diarrhea; elementary school canteen

\section{PENDAHULUAN}

Makanan adalah salah satu kebutuhan mendasar manusia untuk bisa melangsungkan hidupnya selain kebutuhan sandang dan papan. Makanan yang sehat dan aman merupakan salah satu faktor yang penting untuk meningkatkan derajat kesehatan masyarakat. Makanan sehat dan aman adalah makanan yang tidak tercemar, tidak mengandung mikroorganisme atau bakteri dan bahan kimia yang berbahaya, yang telah diolah dengan tata cara yang benar sehingga mutu dan zat gizinya tetap terjaga. Kualitas makanan yang sesuai dengan baku mutu harus selalu dipertahankan agar masyarakat terhindar dari gangguan kesehatan akibat makanan.

Pemerintah sangat memperhatikan masalah penyediaan pangan melalui berbagai sektor, mengingat peranan makanan penting untuk kelangsungan pembangunan. Hal ini disadari bahwa makanan yang tidak memenuhi persyaratan kesehatan akan menimbulkan gangguan kesehatan atau penyakit seperti diare,cholera, disentri, thypus dan keracunan makanan lainnya. Selain itu pula persyaratan kesehatan makanan yang baik dapat mempengaruhi fisik dan intelegensia masyarakat, sehingga dapat meningkatkan kualitas sumber daya manusia yang berdampak pada pembangunan (Azwar, 1990).
Perkembangan kasus diare di Indonesia pada tahun 2008, CFR diare 2,94\% dengan 239 orang meninggal dari 8.133 kasus. Pada tahun 2009 CFR akibat diare sebesar 1,74\% dengan 100 orang meninggal dari 5.756 kasus. Pada tahun 2010 CFR diare $1,74 \%$ dengan jumlah kasus 4.204 dan meninggal sebanyak 73 orang (Depkes RI, 2008, 2009, 2010).Penyebaran diare masih cukup tinggi ditemukan di Provinsi Bali pada tahun 2007 jumlah kasus diare sebesar 21,76 per 100.000 penduduk dan meningkat tahun 2008kasus diare sebesar 22,34 per 100.000 penduduk (Dinas Kesehatan Provinsi Bali, 2008). Kota Denpasar termasuk salah satu daerah di Provinsi Bali yang memiliki kasus diare cenderung meningkat dari tahun 2011 terdapat 11.493 penderita diare dan tahun 2012 terdapat 21.552 penderita diare (Dinas Kesehatan Kota Denpasar Tahun 2013). Kasus diare di Kota Denpasar sesuai kelompok umur 5-14 tahun pada tahun 2012 sebesar 5.200 kasus dan pada tahun 2013 sebesar 5.860 kasus, dengan jumlah kasus terbesar terletak di Denpasar Selatan. Pada tahun 2012 terdapat 1.811 kasus dan tahun 2013 terdapat 2.331 kasus menurut Dinas Kesehatan Provinsi Bali tahun 2013. Salah satu bakteri yang sering dijadikan indikator terjadinya pencemaran makanan adalah bakteri Escherichia coli atau yang lebih dikenal dengan E.coli. Bakteri E. colilazim terdapat dan hidup pada usus manusia yang dianggap 
sebagai bakteri tidak patogen, dan baru menjadi bakteri patogen apabila berada didalam jaringan tubuh di luar usus manusia (Yunaenah, 2009). Pada saat ini sudah banyak ditemukan E.coli dari tinja penderita diare (Ferdiaz,1993).

Dari hasil uji Laboratorium Kesehatan Provinsi Bali terhadap sampel makanan olahan yang diambil dari kantin sekolah, warung dan rumah makan di Wilayah kota Denpasar pada tahun 2013 dengan jumlah sampel yang diambil sebesar 29 sampel terdapat 25 sampel positif E.coli (Dinas Kesehatan Provinsi Bali, 2014).

Dengan melihat potensi makanan jajanan anak Sekolah Dasar yang demikian besar tingkat kerawanan terhadap kontaminasi bakteri E.coli, yang merupakan salah satu bakteri patogen yang dapat menyebabkan penyakit diare, maka berdasarkan pertimbangan tersebut di atas mendorong penulis melakukan penelitian untuk membuktikan adanya kontaminasi E.coli pada makanan jajanan di Kantin Sekolah Dasar di Wilayah Kecamatan Denpasar Selatan yang terjangkit diare paling tinggi pada umur anak sekolah dasar tersebut dan untuk menentukan faktor yang paling dominan berhubungan dengan kejadian kontaminasi E.coli pada makanan jajanan di Kantin Sekolah Dasar Negeri di Wilayah Kecamatan Denpasar Selatan.

\section{METODOLOGI}

\subsection{Rancangan Penelitian}

Penelitian ini dilakukan secara observasi dan wawancara untuk variabel bebas independen (pemilihan bahan makanan, penyimpanan bahan makanan dan makanan jadi, pengolahan makanan, pengangkutan makanan, penyajian makanan, kondisi dan sanitasi bangunan, fasilitas sanitasi dan tenaga penjamah makanan) dan pemeriksaan laboratorium untuk variabel terikat/dependen (makanan jajanan). Penelitian ini bersifat deskriptif analitik dengan pendekatan secara cross sectional yaitu penelitian dimana variabel-variabel bebas dan variabel terikat diukur/diamati pada waktu bersamaan (Murti, 1997).

\subsection{Lokasi dan Waktu Penelitian}

Penelitian ini dilakukan di Wilayah Kecamatan Denpasar Selatan pada 31 kantin Sekolah Dasar Negeri. Pengujian sampel dilakukan di UPT. Laboratorium Kesehatan Provinsi Bali. Penelitian berlangsung selama tiga bulan dimulai bulan Januari sampai dengan bulan Maret 2015.

\subsection{Prosedur Penelitian}

\subsubsection{Melakukan Wawancara Pengelola Kantin di Sekolah Dasar Negeri di Wi l a y a h Kecamatan Denpasar Selatan}

Prosedur penelitian dilakukan dengan wawancara dengan daftar pertanyaan, pengamatan lapangan dan pengambilan data primer di lapangan terkait pengolahan makanan jajanan dan minuman yang terdiri atas beberapa variabel dan indikator yang telah ditentukanformulir inspeksi tempat pengolahan makanan jajanan kantin sekolah dasar (Yunaenah, 2009). Pengukuran dilakukan dengan menggunakan pedoman dimana setiap jawaban " YA" mendapat skor 1, dan jawaban "TIDAK" mendapat skor 0 serta skala ukur yang digunakan adalah nominal.

\subsubsection{Pengukuran keberadaan E.coli pada makanan jajanan dan minuman}

Pengukuran terhadap keberadaan E.coli pada makanan jajanan dan minuman akan dilakukan dua tahap yaitu: Pengambilan sampel makanan jajanan dan minuman pada Kantin Sekolah Dasar Negeri di Wilayah Kecamatan Denpasar Selatan setelah melalui proses peracikan atau pengolahan.Sampel air bersih yang diambil adalah air bersih (selain air PDAM)) yang digunakan untuk memasak dan mencuci peralatan makan pada Kantin Sekolah Dasar. Pengambilan swab dubur dilakukan pada salah satu penyaji makanan jajanan yang bersentuhan langsung dengan anggota tubuh seperti tangan telanjang.

Pemeriksaan E. coli pada makanan jajanan, air bersih dan swab dubur dilakukan dengan pengujian sampel di UPT. Laboratorium Kesehatan Provinsi Bali. Dalam penentuan keberadaan E. coli pada makanan jajanan mengacu pada Keputusan Menteri Kesehatan Republik Indonesia Nomor 1098/Menkes/ SK/VII/2003 tentang Persyaratan Higiene Sanitasi Rumah Makan dan Restoran dan buku Kumpulan Modul Kursus Higiene Sanitasi Makanan dan Minuman yang dikeluarkan oleh Direktorat Janderal Penyehatan Lingkungan Kementerian Kesehatan RI tahun 2012, yang menyatakan bahwa dalam pemeriksaan makanan dan minuman keberadaan E.coli dan bakteri berbahaya (patogen) harus 0 koloni/ml untuk sampel minuman dan 0 koloni/gr untuk sampel makanan. Dalam penentuan kualitas air bersih yang digunakan untuk memasak dan mencuci peralatan makan mengacu pada Peraturan Menteri Kesehatan Republik Indonesia Nomor 416/ Menkes/Per/IX/1990 tentang Persyaratan Kualitas Air Bersih. 
Skala : Nominal. Dikatagorikan menjadi ; Memenuhi Syarat (Air Baku $=0$ koloni $/ 100 \mathrm{ml}$, Air Minum $=0$ koloni/100 ml), Tidak Memenuhi Syarat (Air Baku > 0 koloni/100 ml, Air Minum > 0 koloni/100 ml).

\subsubsection{Prosedur Kerja Pengukuran E.coli}

Makanan padat dihancurkan terlebih dahulu, masukkan 10 gram ke dalam labu erlemeyer berskala dan ditambahkan larutan garam buffer phosphate sebanyak $90 \mathrm{ml}$, lalu dikocok sampai homogen. UntukMakanan cair atau minuman di kocok, dimasukkan $10 \mathrm{ml}$ ke dalam labu erlenmeyer dan ditambahkan $90 \mathrm{ml}$ larutan garam buffer phosphate.Menyiapkan 7 tabung reaksi yang masingmasing berisi media lactose broth sebanyak $10 \mathrm{ml}$. Pada tabung reaksi terdapat pula tabung durham. Tabung disusun pada rak tabung reaksi, masingmasing tabung diberi tanda sebagai berikut: nomor urut, volume, dan tanggal pemeriksaan untuk tes perkiraan. Mengambil bahan yang diperiksa dengan pipet steril dimasukkan ke dalam tabung 1 s/d 5 masing-masing sebanyak $10 \mathrm{ml}$, tabung ke 6 sebanyak $1 \mathrm{ml}$ dan tabung ke 7 sebanyak 0,1 ml. Masing - masing tabung digoyang agar spesimen dan media bercampur rata. Diinkubasi pada suhu $35^{\circ} \mathrm{C}$ $37^{\circ} \mathrm{C}$ selama $24 \mathrm{jam}$. Setelah 24 jam diperiksa ada tidaknya gas pada tabung durham. Adanya gas pada tabung durham menunjukkan tes pendahuluan positif, yang kemudian dilanjutkan dengan test penegasan.

Test penegasan dengan menggunakan media Brilliant Green Lactose Bile broth 2 \% (BGLB broth $2 \%)$. Dari tiap-tiap tabung yang positif, dipindahkan 1-2 ose kedalam tabung yang berisi $10 \mathrm{ml} \mathrm{BGLB} 2 \%$. Tabung tersebut lalu diinkubasikan pada suhu $44^{\circ} \mathrm{C}$ selama 24 jam (untuk memastikan adanya $E$. coli tinja). Melakukan pembacaan setelah 24-48 jam dengan melihat tabung BGLB $2 \%$ yang menunjukkan positif gas. Mengambil sampel awal yang telah di encerkan sebanyak $10^{-1}$ dengan pipet $10 \mathrm{ml}$ dan dimasukkan ke dalam media BHI broth, lalu diinkubasi pada suhu $44^{\circ} \mathrm{C}$ selama 2 jam. Pindahkan 1 ose koloni ke dalam media selektif (Mac Conkey Agar) dan diinkubasi pada suhu $37^{\circ} \mathrm{C}$ selama 24 jam.Koloni tersangka ( berwarna merah jingga atau pink-hitam metalik, besar, cembung dan mengkilat) dipindahkan 1 ose ke media KIA miring dan MIU agar dan diinkubasi selama 24 jam pada suhu $35^{\circ} \mathrm{C}-37^{\circ} \mathrm{C}$ selama 24 jam. Pada koloni tersangka (KIA berwarna atas dan bawah berwana kuning, MIU tidak terdapat gas $\mathrm{H}_{2} \mathrm{~S}$ ) dilakukan uji oxidase, indol, dan urease, kemudian dibaca, jika hasil uji sesuai dengan pedoman hasil uji (Depkes RI, 1991), maka sampel dinyatakan positif mengandung E.coli.

\section{HASIL DAN PEMBAHASAN}

\subsection{Kontaminasi E.coli Pada Makanan Jajanan di Kantin Sekolah}

Pengambilan sampel makanan jajanan berupa makanan padat (nasi goreng sayur atau mie goreng sayur) dan makanan cair (es teh sisri, es rujak atau es gula) pada 31 di Kantin Sekolah Dasar Negeri di Wilayah Kecamatan Denpasar Selatan dengan menggunakan plastik steri, yang selanjutnya dilakukan pemeriksaan di Laboratorium Dinas Kesehatan Provinsi Bali. Berdasarkan hasil uji terhadap kontaminasi E.coli pada sampel makanan jajanan tersebut, diperoleh $71 \%$ kantin positif terkontaminasi E.coli dan $29 \%$ negatif terkontaminasi E.coli seperti pada Tabel 1.

\subsection{Kondisi Variabel Bebas Di Kantin Sekolah Dasar Negeri di Wilayah Kecamatan Denpasar Selatan}

Pada umumnya kondisi kantin di Sekolah Dasar Negeri di Wilayah Kecamatan Denpasar Selatan letaknya berada di belakang dan selalu berdekatan dengan toilet, tidak memiliki tempat pencucian bahan makanan, peralatan dan pencucian tangan yang memadai, bahan makanan (sayur-sayuran) diperoleh dari pasar tradisional, pengolahan makanan di ruang terbuka, masih banyak yang mempergunakan air sumur dan adanya kebiasaan penjamah makanan yang pegang HP serta tidak mencuci tangan. Berdasarkan hasil observasi dan wawancara dengan menggunakan formulir inpeksi sanitasi tempat pengolahan makanan jajanan di Kantin Sekolah Dasar di Wilayah Kecamatan Denpasar Selatan (Yunaenah, 2009), maka diperoleh hasil penelitian terhadap kondisi variabel bebas di Kantin Sekolah Dasar Negeri di Wilayah Kecamatan Denpasar Selatan seperti pada Tabel 2.

\subsection{Hasil Analisis Bivariat}

Variabel bebas yang dianalisis dengan menggunakan analisis bivariat meliputi: bahan makanan, penyimpanan bahan makanan, pengolahan makanan, penyimpanan makanan matang, pengangkutan makanan, penyajian makanan, kondisi dan sanitasi bangunan, fasilitas sanitasi, tenaga penjamah makanan. Variabel terikat adalah kontaminasi E.coli. Berdasarkan analisis bivariat tersebut diperoleh variabel bebas yang menunjukkan hubungan bermakna dengan kontaminasi E.coli adalah bahan makanan yang akan diolah $(p=0,037)$, penyimpanan bahan makanan $(p=0,041)$, pengolahan makanan $(p=0,037)$, fasilitas sanitasi $(p=0,015)$ dan tenaga penjamah $(p=0,037)$ yang dapat ditunjukkan pada Tabel 3. 
Tabel 1.Distribusi Sampel Menurut Kontaminasi E.coli Pada Makanan Jajanan diKantin Sekolah Dasar Negeri di Wilayah Kecamatan Denpasar Selatan

\begin{tabular}{lcc}
\hline Kontaminasi E.coli & Jumlah & Persentase (\%) \\
\hline Positif & 22 & 71 \\
Negatif & 9 & 29 \\
Jumlah & 31 & 100 \\
\hline
\end{tabular}

Tabel 2. Distribusi kondisi variabel bebas di Kantin Sekolah Dasar Negeri di WilayahKecamatan Denpasar Selatan

\begin{tabular}{lccccc}
\hline Variabel Bebas & Memenuhi Syarat & $\%$ & Tdk Memenuhi Syarat & $\%$ & Jumlah \\
\hline Bahan makanan & 9 & 29,0 & 22 & 71,0 & 31 \\
Penyimpanan bahan makanan & 12 & 38,7 & 19 & 61,3 & 31 \\
Pengolahan makanan & 9 & 29,0 & 22 & 71,0 & 31 \\
Penyimpanan makanan matang & 26 & 83,9 & 5 & 16,1 & 31 \\
Pengangkutan makanan matang & 26 & 83,9 & 5 & 16,1 & 31 \\
Penyajian makanan & 17 & 54,8 & 14 & 45,2 & 31 \\
Kondisi dan sanitasi bangunan & 10 & 32,3 & 21 & 67,7 & 31 \\
Fasilitas sanitasi & 8 & 25,8 & 23 & 74,2 & 31 \\
Tenaga penjamah makanan & 9 & 29,0 & 22 & 71,0 & 31 \\
\hline
\end{tabular}

Tabel 3. Tabel Silang Antara Variabel Bebas Dengan Kontaminasi E.colidi KantinSekolah Dasar Negeri di Wilayah Kecamatan Denpasar Selatan

\begin{tabular}{|c|c|c|c|c|c|c|c|c|c|}
\hline \multirow{3}{*}{ Variabel bebas } & \multirow{3}{*}{ Kondisi } & \multicolumn{4}{|c|}{ Kontaminasi E.coli } & \multirow{3}{*}{ Jumlah } & \multirow{3}{*}{$p$} & \multirow{3}{*}{$\mathrm{X}^{2}$} & \multirow{3}{*}{ OR } \\
\hline & & \multicolumn{2}{|c|}{ Positif } & \multicolumn{2}{|c|}{ Negatif } & & & & \\
\hline & & $n$ & $\%$ & $\mathrm{n}$ & $\%$ & & & & \\
\hline \multirow[t]{2}{*}{ Bahan Makanan } & Memenuhi syarat & 4 & 18,2 & 5 & 55,6 & 9 & 0,037 & 4,330 & 5,625 \\
\hline & Tdk memenuhi syarat & 18 & 81,8 & 4 & 44,4 & 22 & & & \\
\hline \multirow{2}{*}{ Penyimpanan bahan makanan } & Memenuhi syarat & 6 & 27,3 & 6 & 66,7 & 12 & 0,041 & 4,178 & 5,333 \\
\hline & Tdk memenuhi syarat & 16 & 72,7 & 3 & 33,3 & 19 & & & \\
\hline \multirow[t]{2}{*}{ Pengolahan makanan } & Memenuhi syarat & 4 & 18,2 & 5 & 55,6 & 9 & 0,037 & 4,330 & 5,625 \\
\hline & Tdk memenuhi syarat & 18 & 81,8 & 4 & 44,4 & 22 & & & \\
\hline \multirow[t]{2}{*}{ Penyimpanan makanan matang } & Memenuhi syarat & 18 & 81,8 & 8 & 88,9 & 2 & 0,627 & 0,236 & 1,778 \\
\hline & Tdk memenuhi syarat & 4 & 18,2 & 1 & 18,2 & 5 & & & \\
\hline \multirow[t]{2}{*}{ Pengangkutan makanan matang } & Memenuhi syarat & 18 & 81,8 & 8 & 88,9 & 26 & 0,627 & 0,236 & 1,778 \\
\hline & Tdk memenuhi syarat & 4 & 18,2 & 1 & 11,1 & 5 & & & \\
\hline \multirow[t]{2}{*}{ Penyajian makanan } & Memenuhi syarat & 11 & 50 & 6 & 66,7 & 17 & 0,397 & 0,716 & 2,0 \\
\hline & Tdk memenuhi syarat & 11 & 50 & 3 & 33,3 & 14 & & & \\
\hline \multirow[t]{2}{*}{ Kondisi dan sanitasi bangunan } & Memenuhi syarat & 5 & 22,7 & 5 & 55,6 & 10 & 0,076 & 3,150 & 4,250 \\
\hline & Tdk memenuhi syarat & 17 & 77,3 & 4 & 44,4 & 21 & & & \\
\hline \multirow[t]{2}{*}{ Fasilitas sanitasi } & Memenuhi syarat & 3 & 13,6 & 5 & 55,6 & 8 & 0,015 & 5,862 & 7,917 \\
\hline & Tdk memenuhi syarat & 19 & 86,4 & 4 & 44,4 & 23 & & & \\
\hline \multirow[t]{2}{*}{ Tenaga penjamah makanan } & Memenuhi syarat & 4 & 18,2 & 5 & 55,6 & 9 & 0,037 & 4,330 & 5,625 \\
\hline & Tdk memenuhi syarat & 18 & 81,8 & 4 & 44,4 & 22 & & & \\
\hline
\end{tabular}

3.4. Analisis Faktor Dominan Yang Berhubungan Dengan Kejadian KontaminasiE.coli Pada Makanan Jajanan Di Kantin Sekolah Dasar Negeri di Wilayah Kecamatan Denpasar Selatan.

Hasil analisis multivariat menunjukkan bahwa bahwa fasilitas sanitasi merupakan faktor dominan yang berhubungan dengan kejadian kontaminasi E.coli pada makanan jajanan di Kantin Sekolah Dasar Negeri di Wilayah Kecamatan Denpasar Selatan dengan nilai $\mathrm{p}=0,024$, dengan nilai $\mathrm{OR}$ sebesar 7,917 yang dapat dilihat pada Tabel 4.

Pada analisis multivariat fasilitas sanitasi yang meliputi : kesediaan air bersih, penanganan sampah, penanganan air limbah, kebersihan toilet, tempat cuci tangan dan peralatan merupakan faktor dominan yang berhubungan dengan kejadian kontaminasi E.coli pada makanan jajanan di Kantin Sekolah Dasar Negeri di Wilayah Kecamatan Denpasar Selatan dengan nilai $p=0,024$, dengan nilai OR sebesar 7,917.

Kantin Sekolah Dasar Negeri di Wilayah Kecamatan Denpasar Selatan pada umumnya masih menggunakan air sumur, memiliki tempat sampah yang terbuka, saluran limbah yang masih terbuka dan tempat cuci tangan tidak menggunakan air 
Tabel 4. Nilai Standard Error, Exp (B), Cl dan Nilai P value Variabel Bebas YangBerhubungan Dengan Kejadian Kontaminasi E.coli Pada Makanan Jajanandi Kantin SDN di Wilayah Kecamatan Denpasar Selatan

\begin{tabular}{|c|c|c|c|c|c|}
\hline \multirow{2}{*}{ Variabel Bebas } & \multirow{2}{*}{ SE } & \multirow{2}{*}{$P$ (value) } & \multirow{2}{*}{$\operatorname{Exp}(B)$} & \multicolumn{2}{|c|}{ Cl $95 \%$} \\
\hline & & & & Lower & Upper \\
\hline Fasilitas Sanitasi & 0,914 & 0,024 & 7,917 & 1,319 & 47,512 \\
\hline
\end{tabular}

mengalir sehingga terjadi rekontaminasi (kontaminasi ulang).

Penyediaan air bersih yang memenuhi syarat sangat berpengaruh terhadap proses pengolahan makanan, karena air dibutuhkan pada semua proses produksi makanan. mulai dari pencucian bahan, pencucian peralatan, pengolahan dan penyajian makanan. Apabila kualitas air tidak memenuhi syarat kesehatan maka dapat menyebabkan kontaminasi terhadap makanan. Kondisi air cucian maupun air yang digunakan dalam proses makanan lebih banyak menggunakan air yang kurang memenuhi standar, sehingga saat pencucian peralatan maupun penggunaan peralatan untuk mengkonsumsi makanan dan minuman diduga sudah terkontaminasi bakteri E.coli.

Fasilitas sanitasi adalah sarana dan kelengkapan yang harus tersedia untuk memelihara kualitas lingkungan atau mengendalikan faktorfaktor lingkungan fisik yang dapat menyebabkan pencemaran terhadap makanan.

\section{SIMPULAN DAN SARAN}

\subsection{Simpulan}

Berdasarkan hasil penelitian mengenai faktorfaktor yang mengkontaminasi E.coli pada makan jajanan di Kantin Sekolah Dasar Negeri di Wilayah Kecamatan Denpasar Selatan, maka dapat disimpulkan sebagai berikut:Makanan jajanan di Kantin Sekolah Dasar Negeri di Wilayah Kecamatan Denpasar Selatan mayoritas (71\%) terkontaminasi E.coli.Faktor yang paling dominan berhubungan dengan kontaminasi E.coli pada makanan jajanan di Kantin Sekolah Dasar di Wilayah Kecamatan Denpasar Selatan adalah faktor fasilitasi sanitasi khususnya faktor air yang di manfaatkan.

\subsection{Saran}

Disarankan semua kantin Sekolah Dasar Negeri di Wilayah Denpasar selatan untuk meningkatkan sanitasi lingkungan dan menggunakan sumber air yang lebih higienis, seperti air PAM.

Perlu dilakukan pembinaan dari segi peningkatan pengetahuan, ketrampilan dan sikap pengelola kantin sekolah mengenai higiene dan sanitasi makanan serta perlu dilakukan monitoring terhadap makanan jajanan di kantin-kantin sekolah secara periodik.

\section{DAFTAR PUSTAKA}

Azwar. 1990. Pengantar Ilmu Kesehatan Lingkungan. PT. Mutiara Sumber Widia, Jakarta.

Depkes RI. 1991. Petunjuk Pemeriksaan Mikrobiologi Makanan dan Minuman, Jakarta.

Depkes RI. 2008. Profil Kesehatan Indonesia, Jakarta

Depkes RI. 2009. Profil Kesehatan Indonesia, Jakarta.

Depkes RI. 2010. Profil Kesehatan Indonesia, Jakarta.

Dinas Kesehatan Kota Denpasar. 2013. Profil Dinas Kesehatan Kota Denpasar, Denpasar.

Dinas Kesehatan Provinsi Bali. 2014. Hasil Uji Makanan Olahan Pada Warung, Rumah Makan dan Kantin Sekolah, UPT. Labkes. Provinsi Bali, Denpasar.

Ferdiaz, S. 1993. Analisis Mikrobiologi Pangan. Raja Grafindo Perkasa, Jakarta.

Kusumayati, A. 2002. Manajemen Penyehatan Makanan. Fakultas Kesehatan Masyarakat, Universitas Indonesia, Depok, Jakarta.

Menteri Kesehatan Republik Indonesia. 1990.Peraturan Menteri Kesehatan RI Nomor : 416/Menkes /Per/IX/1990 tentang Persyaratan Kualitas Air Bersih, Jakarta.

Murti, B. 1997. Prinsip dan Metode Riset Epidemiologi. Gajah Mada University Press, Yogyakarta.

Menteri Kesehatan Republik Indonesia. 2003. Keputusan Menteri Kesehatan RI No. 942 Tahun 2003 tentang Persyaratan Hygiene Sanitasi Makanan Jajanan, Jakarta.

Menteri Kesehatan Republik Indonesia. 2003. Keputusan Menteri Kesehatan RI No. 1098 Tahun 2003 tentang Persyaratan Hygiene Sanitasi Rumah Makan dan Restoran, Jakarta.

Menteri Kesehatan Republik Indonesia. 2012. Kumpulan Modul Kursus Higiene Sanitasi Makanan dan Minuman, Subdit Sanitasi Makanan dan Bahan Pangan, Ditjen PP dan PL. Jakarta.

Yunaenah, 2009. Kontaminasi E.coli Pada Makanan Jajanan di Kantin Sekolah Dasar Wilayah Jakarta Pusat. Tesis FKM UI Depok, Jakarta. 